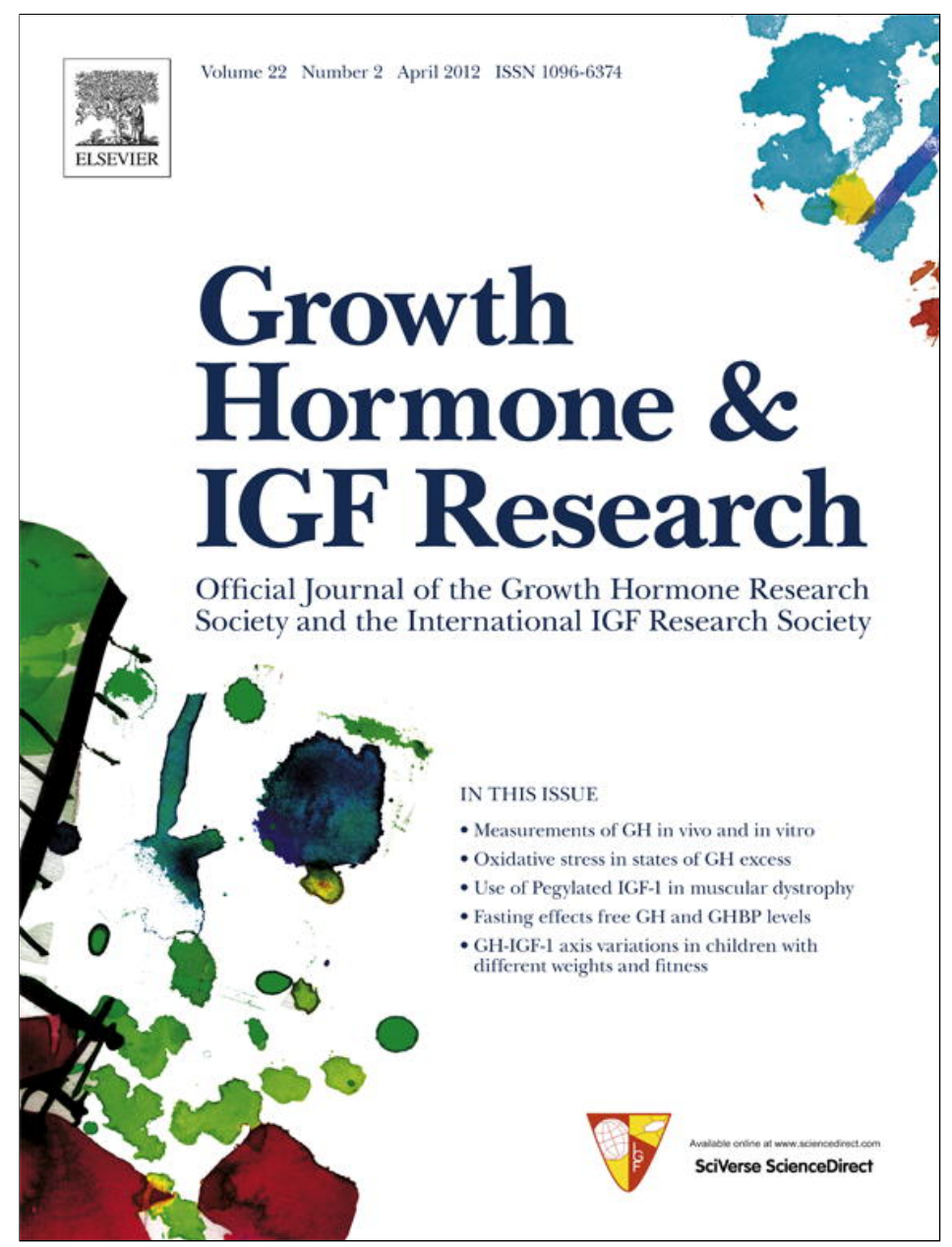

This article appeared in a journal published by Elsevier. The attached copy is furnished to the author for internal non-commercial research and education use, including for instruction at the authors institution and sharing with colleagues.

Other uses, including reproduction and distribution, or selling or licensing copies, or posting to personal, institutional or third party websites are prohibited.

In most cases authors are permitted to post their version of the article (e.g. in Word or Tex form) to their personal website or institutional repository. Authors requiring further information regarding Elsevier's archiving and manuscript policies are encouraged to visit:

http://www.elsevier.com/copyright 


\title{
Janus kinase (JAK) 2 V617F mutation as the cause of primary thrombocythemia in acromegaly with severe visceromegaly and divergence between growth hormone and insulin-like growth factor-1 concentrations during the follow-up: causal or casual association?
}

\author{
Alessandro Ciresi a , Valentina Guarnotta ${ }^{a}$, Laura Tomasello ${ }^{a}$, Valentina Calò ${ }^{b}$, Antonio Russo ${ }^{b}$, \\ Aldo Galluzzo ${ }^{a}$, Carla Giordano ${ }^{\text {a,* }}$ \\ a Section of Endocrinology, Laboratory of Molecular Endocrinology, Biomedical Department of Internal and Specialist Medicine (DIBIMIS), University of Palermo, Palermo, Italy \\ b Genetic and Molecular Clinical Oncology Unit, Department of Surgical and Oncological Sciences, University of Palermo, Palermo, Italy
}

\section{A R T I C L E I N F O}

\section{Article history:}

Received 29 June 2011

Received in revised form 26 December 2011

Accepted 1 February 2012

Available online 22 February 2012

\section{Keywords:}

Acromegaly

Growth hormone

Insulin-like growth factor-1

Janus kinase 2

Growth hormone receptor

\begin{abstract}
A B S T R A C T
Objective: An increased prevalence of hematological abnormalities is reported in acromegaly, but to date no reports about the presence of the Janus Kinase (JAK) 2 mutation in acromegalic patients have been described. Design: We report the complex clinical presentation of the unique case, never described, of acromegaly due to GH-secreting pituitary adenoma associated with JAK2 V617F mutation.

Results: The patient shows primary thrombocythemia and myelofibrosis, due to JAK2 V617F mutation, severe visceromegaly and a peculiar clinical course of the disease characterized by discrepant values of GH and IGF-1 during somatostatin analog (SA) treatment despite a significant reduction in pituitary adenoma size and therapeutic resistance both to SA and pegvisomant.

Conclusions: The presence of JAK2 V617F mutation is a cause of primary thrombocythemia and myelofibrosis in acromegaly. In this patient, a peculiar clinical course of acromegaly was observed, with the difficulty in controlling the disease. More data, on a larger cohort of patients, could clarify whether JAK2 V617F mutation has a serious impact on the clinical features and course of acromegaly.
\end{abstract}

(c) 2012 Elsevier Ltd. All rights reserved.

\section{Introduction}

Growth hormone $(\mathrm{GH})$ actions are mediated via the $\mathrm{GH}$ receptor (GHR) and their interaction leads to phosphorylation of the tyrosine residues of Janus kinase (JAK) 2, with subsequent phosphorylation of signal transducers and activators of transcription (STATs) and activation of Ras mitogen-activated-protein kinase pathways [1,2]. In 2005, Kralovics et al. reported the results of an analysis of the JAK2 gene in patients with myeloproliferative neoplasms, observing a dominant gain-of-function mutation in which valine at position 617 was replaced by phenylalanine (V617F) in the majority of patients [3]. This mutation identifies a subset of patients affected by essential thrombocythemia and polycythemia vera who are predisposed to thrombosis and myelofibrosis, and appears to render hemopoietic cells more sensitive to growth factors [4]. The prevalence and clinical

\footnotetext{
* Corresponding author at: Biomedical Department of Internal and Specialist Medicine (DIBIMIS), Section of Endocrinology, University of Palermo, Piazza delle Cliniche 2, 90127 Palermo, Italy. Tel.: + 39091 6552109; fax: + 390916552123.

E-mail address: cgiordan@unipa.it (C. Giordano).
}

significance of JAK2 V617F in the general population is unknown and it may also be prevalent in individuals without overt signs of myeloproliferative cancer $[5,6]$. The excessive chronic activation of the GHR-JAK2 pathway by high circulating levels of $\mathrm{GH}$ results in acromegaly, whereas cell transformation and cancer can occur in response to autocrine activation of the receptor. In acromegaly, an increased prevalence of hematological abnormalities and lymphohematopoietic neoplasms is described, including polycythemia vera, lymphoma, multiple myeloma, chronic myelogenic or lymphocytic leukemia [7-10], but to date there are no reports describing the presence of the JAK2 mutation in acromegaly. Similarly, no data about GH and IGF-1 levels and their feedback regulation in non-acromegalic patients that are carriers of the JAK2 mutation are available in the literature. On the other hand, several studies have reported a varying prevalence of discrepancy between GH and IGF-I concentrations in acromegalic patients both at diagnosis and during the follow-up. The mechanisms underlying this discordance have not been fully explored [11-14], although it has been proposed that factors such as age, gender, prior radiotherapy and the GHR polymorphism may be able to modify the relationship between GH and IGF-I [15-18]. We report the unique case of an acromegalic patient with JAK2 V617F mutation and the clinical and hormonal consequences of these two associated conditions. 


\section{Materials and methods}

\subsection{Clinical parameters}

A 72-year-old man, a former smoker, was admitted 18 months ago to our Endocrine Unit because of recent evidence of weakness and dyspnea after exercise and fasting hyperglycemia. Table 1 shows the patient's clinical features. He complained of having had headache, diffuse arthralgia, nocturnal polyuria and slight dysphagia for at least 1 year. At clinical examination he had seborrheic skin and hair, high levels of systolic and diastolic blood pressure (170 and $95 \mathrm{~mm}$ $\mathrm{Hg}$, respectively) and arrhythmic heart rate (78 bpm). No significant change in weight was reported. Prognathism, macroglossia, large hands and feet and multinodular goiter were detected.

\subsection{Biochemical and instrumental parameters}

Routine laboratory tests showed high platelet count $\left(682 \times 10^{9} / \mathrm{L}\right.$; normal value 150-450) and normocytic anemia. Basal hormonal evaluation revealed normal thyroid hormones, elevated IGF-I $(918 \mu \mathrm{g} / \mathrm{L}$, age and sex-matched normal $78-200)$ and high mean basal GH levels ( $37 \mu \mathrm{g} / \mathrm{L}$ ), with absence of GH suppression to the oral glucose tolerance test (OGTT) (GH nadir $7.68 \mu \mathrm{g} / \mathrm{L}$ ). The remaining pituitary function was normal. OGTT showed frank diabetes mellitus with hyperinsulinism (serum insulin peak during OGTT $212 \mathrm{IU} / \mathrm{ml}$ ) and glycosylated hemoglobin (HbA1c) level was 7.5\%. A magnetic resonance imaging (MRI) scan showed a pituitary macroadenoma (tumor volume $2.59 \mathrm{~cm}^{3}$ ). Two indications of positivity for fecal occult blood test samples, high levels of carcinoembryonic antigen (CEA), colonscopy finding of multiple colorectal adenomatous polyps and contextual biopsy led to the diagnosis of tubular adenoma with low- grade dysplasia. Visual field evaluation showed normal findings. Concentric biventricular hypertrophy with normal ejection fraction was detected by echocardiography. Ultrasonic evaluation showed an increase in carotid intima-media thickness with multiple carotid plaques and a multinodular goiter, while computerized axial tomography showed severe visceromegaly, with increased spleen, liver, bile ducts and Wirsung size, multicystic dysplastic kidneys, a pancreatic cyst of $30 \mathrm{~mm}$ and a left adrenal nodule of $15 \mathrm{~mm}$ (Fig. 1). High platelet count having been confirmed $\left(639 \times 10^{9} / \mathrm{L}\right)$, after consulting with hematologists the analysis of the JAK2 gene was performed and the presence of the V617F mutation was confirmed. The patient underwent osteomedullary biopsy of the iliac crest and evidence of $40 \%$ bone marrow cellularity with megakaryocytic hyperplasia and increased medullary fibrosis led to a diagnosis of primary myelofibrosis.

We administered metformin, sartan, aspirin and octreotide long acting release (LAR) as first-line medical treatment, with intramuscular injections of $20 \mathrm{mg}$ every 28 days.

\subsection{Detection of JAK2 V617F mutation}

Genomic DNA was extracted from whole unfractionated peripheral blood samples according to the instructions contained in the QIAamp Blood Kit (Qiagen, Hilden, Germany). 25 ng of sample genomic DNA was added to the amplification mixture using the JAK2 MutaScreen assay (Ipsogen, Luminy Biotech, Marseille, France) on ABI PRISM 7900 (Applied Biosystems, Foster City, CA). This assay is based on the use of 2 specific TaqMan probes and the measurement of the respective fluorescence of the 2 alleles (FAM for V617F and VIC for wild-type) to differentiate the amplification of each allele. The mean ratio of mutant to wild-type allele was calculated for patient sample and was compared with the mean ratio of the reference sample provided.

Table 1

Clinical and biochemical features of patient at diagnosis and during the treatment. LAR: octreotide-long acting release; PEG-V: pegvisomant.

\begin{tabular}{|c|c|c|c|c|c|c|}
\hline \multicolumn{7}{|c|}{ Symptoms and signs at diagnosis } \\
\hline \multicolumn{7}{|l|}{ Weakness } \\
\hline \multicolumn{7}{|l|}{ Dyspnea } \\
\hline \multicolumn{7}{|l|}{ Headache } \\
\hline \multicolumn{7}{|l|}{ Diffuse arthralgia } \\
\hline \multicolumn{7}{|l|}{ Dysphagia } \\
\hline \multicolumn{7}{|l|}{ Seborrheic skin and hair } \\
\hline \multicolumn{7}{|l|}{ Prognathism } \\
\hline \multicolumn{7}{|l|}{ Macroglossia } \\
\hline \multicolumn{7}{|l|}{ Enlarged hands and feet } \\
\hline \multicolumn{7}{|l|}{ Diabetes mellitus } \\
\hline \multicolumn{7}{|l|}{ Hyperinsulinemia } \\
\hline \multicolumn{7}{|c|}{ Systolic and diastolic hypertension } \\
\hline \multicolumn{7}{|c|}{ Cardiac arrhythmia } \\
\hline \multicolumn{7}{|l|}{ Multinodular goiter } \\
\hline \multicolumn{7}{|l|}{ Multiple colorectal polyps } \\
\hline \multicolumn{7}{|l|}{ Cardiac hypertrophy } \\
\hline \multicolumn{7}{|l|}{ Atherosclerosis } \\
\hline \multicolumn{7}{|l|}{ Hepatomegaly } \\
\hline \multicolumn{7}{|l|}{ Splenomegaly } \\
\hline \multicolumn{7}{|l|}{ Multicystic kidneys } \\
\hline \multicolumn{7}{|l|}{ Pancreatic cyst } \\
\hline \multicolumn{7}{|l|}{ Nodular adrenal hyperplasia } \\
\hline \multicolumn{7}{|l|}{ Biochemical parameters } \\
\hline & Pre-treatment & $\begin{array}{l}\text { After } 6 \text { months } \\
\text { of LAR } 20 \mathrm{mg}\end{array}$ & $\begin{array}{l}\text { After } 4 \text { months } \\
\text { of LAR } 30 \mathrm{mg}\end{array}$ & $\begin{array}{l}\text { After } 3 \text { months } \\
\text { of PEG-V } 10 \mathrm{mg}\end{array}$ & $\begin{array}{l}\text { After } 3 \text { months } \\
\text { of PEG-V } 15 \mathrm{mg}\end{array}$ & $\begin{array}{l}\text { After } 1 \text { month } \\
\text { of PEG-V } 20 \mathrm{mg}\end{array}$ \\
\hline Platelet count (n.v.150-450) & $682 \times 109 / \mathrm{L}$ & $651 \times 109 / \mathrm{L}$ & $612 \times 109 / \mathrm{L}$ & - & - & - \\
\hline IGF-I ( $\mu \mathrm{g} / \mathrm{L})($ n.v. 78-200) & 918 & 715 & 750 & 610 & 590 & 601 \\
\hline Mean basal GH $(\mu \mathrm{g} / \mathrm{L})$ & 37 & 4.5 & 2.2 & - & - & - \\
\hline GH nadir (after OGTT) $(\mu \mathrm{g} / \mathrm{L})$ & 7.68 & 1.2 & 0.3 & - & - & - \\
\hline HbA1c (\%) (n.v. < 5.5) & 7.5 & 7.3 & 7.4 & 7.7 & 7.4 & 7.5 \\
\hline Tumor volume $\left(\mathrm{cm}^{3}\right)$ & 2.59 & - & 1.76 & - & - & - \\
\hline
\end{tabular}

n.v.: normal value. 


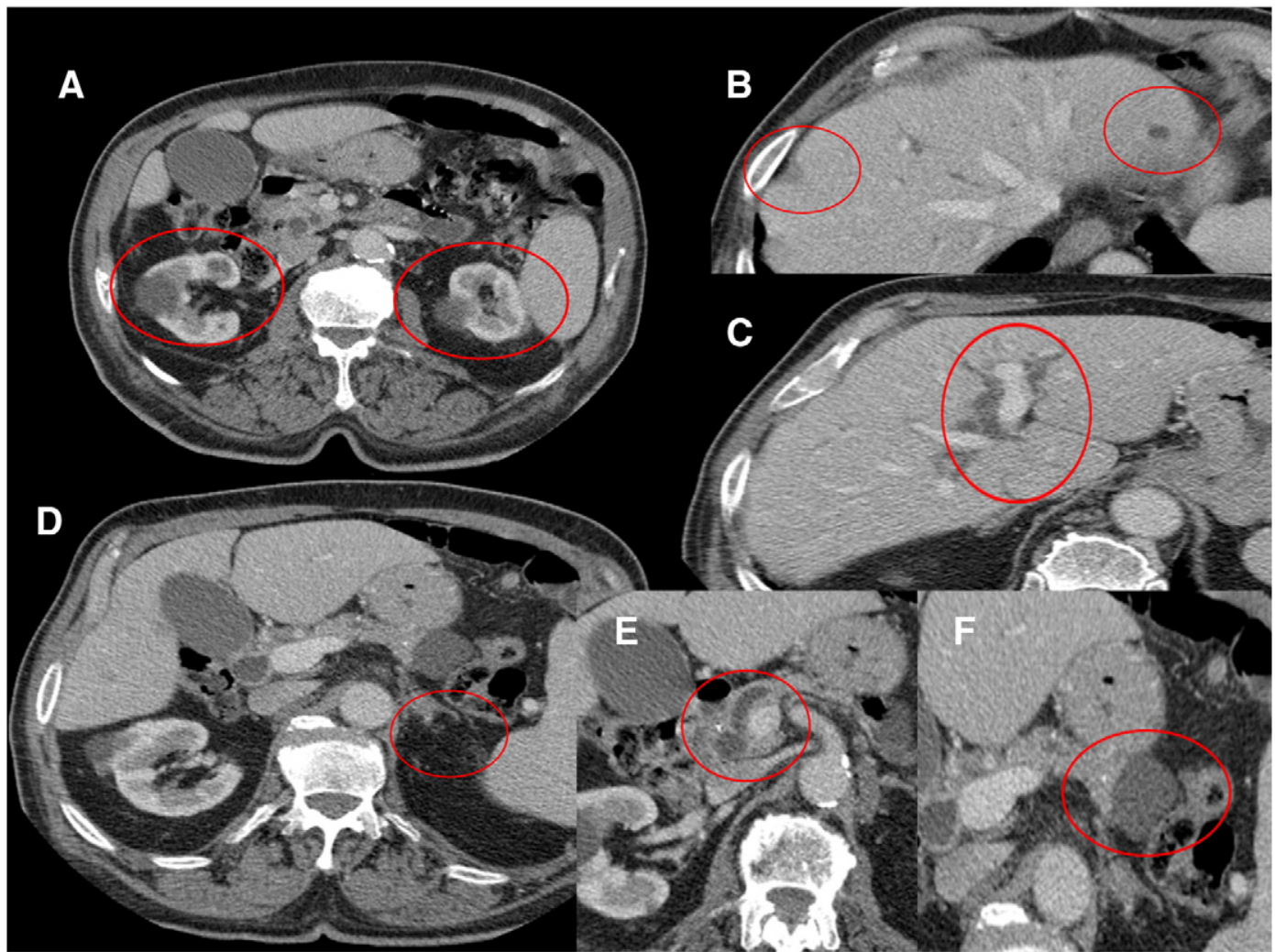

Fig. 1. Severe visceromegaly detected by computerized axial tomography: multicystic dysplastic kidneys (A); multicystic liver (B); increased bile ducts size (C); 15 -mm left adrenal nodule (D); increased Wirsung size (E); 30-mm pancreatic cyst (F).

\subsection{Hormone and biochemical assays}

Serum GH levels were determined by immunoradiometric assay (IRMA) (Immulite; Diagnostic Products Corp., Los Angeles, CA), with an assay sensitivity of $0.05 \mu \mathrm{g} / \mathrm{L}$. Serum IGF-1 was measured using IRMA (Diagnostic System Laboratories Inc., Webster, TX), with an assay sensitivity of $0.8 \mu \mathrm{g} / \mathrm{L}$. The normal range for age and sex was $78-200 \mu \mathrm{g} / \mathrm{L}$. Hemochrome was measured in our centralized laboratory with standard methods. The normal value for platelet count is $150-450 \times 10^{9} / \mathrm{L}$

\section{Results}

\subsection{6 months-follow-up}

After the first 6 months of monthly LAR $20 \mathrm{mg}$, the patient showed only a slight reduction in HbA1c levels (7.3 vs. 7.5\%), without benefit for the platelet count $(651 \times 109 / \mathrm{L})$ and no full normalization of hormonal parameters (basal GH $4.5 \mu \mathrm{g} / \mathrm{L}$, GH nadir $1.2 \mu \mathrm{g} / \mathrm{L}$ IGF1-1 $715 \mu \mathrm{g} / \mathrm{L})$. Because of IGF-1 being persistently above the normal range, despite significantly decreased basal GH levels, the dose of octreotide-LAR was increased to $30 \mathrm{mg} / \mathrm{month}$.

\subsection{0 months-follow-up}

After another 4 months of treatment, IGF-1 was still above the normal range $(750 \mu \mathrm{g} / \mathrm{L})$, but with concomitant "safe" mean basal $(2.2 \mu \mathrm{g} / \mathrm{L})$ and nadir $\mathrm{GH}(0.3 \mu \mathrm{g} / \mathrm{L})$. The platelet count remained high $(612 \times 109 / \mathrm{L})$ and $\mathrm{HbA} 1 \mathrm{c}$ above the normal range $(7.4 \%)$ despite the full dose of metformin, while MRI showed a $32 \%$ decrease in tumor mass (1.76 vs. $2,59 \mathrm{~cm}^{3}$ ) (Fig. 2). Based on persistent high IGF-1 levels, octreotide therapy was stopped and the patient started pegvisomant (PEG-V) treatment at an initial daily dose of $10 \mathrm{mg}$, increased to $15 \mathrm{mg}$ after 3 months because of failure to achieve the target IGF-1 level $(610 \mu \mathrm{g} / \mathrm{L})$.

\subsection{6-17 months-follow-up}

Recently, after another 3 months with a daily dose of $15 \mathrm{mg}$, due to evidence of IGF-1 being well above the normal range $(590 \mu \mathrm{g} / \mathrm{L})$, we increased the daily dose of PEG-V to $20 \mathrm{mg}$, but after 30 days of treatment a slight elevation of serum concentrations of alanine aminotransferase and aspartate aminotransferase, not greater than twice the upper limit of normal, was observed, with concomitant lack of decrease in IGF-1 (601 $\mu \mathrm{g} / \mathrm{L})$. Notably, HbA1c levels remained well above the normal range also after the start of PEG-V treatment (7.7\%, $7.4 \%$ and $7.5 \%$ after daily dose of 10,15 and $20 \mathrm{mg}$, respectively).

Table 1 shows the patient's biochemical features during the treatments. The graphic representation of GH and IGF-1 levels is shown in Fig. 3. The follow-up of the disease is ongoing.

\section{Discussion}

In acromegaly, an increased risk of hematological abnormalities and lymphohematopoietic neoplasms is described as a secondary manifestation of the disease and usually regresses after the disease is treated $[7,19]$. By contrast, primary hematological abnormalities in acromegaly are rarely reported on nor, to date, have the presence of the JAK2 V617F mutation, known as a cause of essential thrombocythemia and polycythemia vera, ever been reported on. JAK2 V617F mutation is observed in about $60-65 \%$ of patients with essential thrombocythemia. In these patients, because signaling by the mutated kinase utilizes normal pathways, the result is an overproduction of 


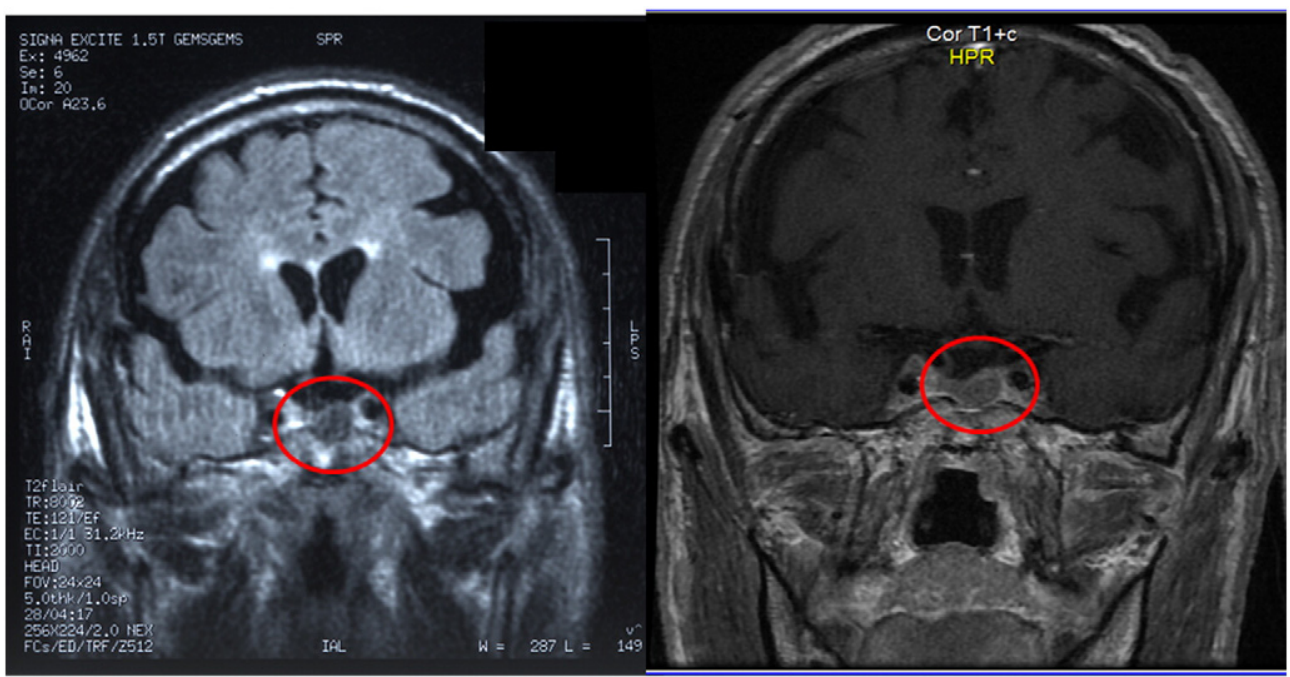

Fig. 2. MRI showing pituitary adenoma at diagnosis $\left(2.59 \mathrm{~cm}^{3}\right)$ and after 10 months of octreotide LAR $\left(1.76 \mathrm{~cm}^{3}\right)$.

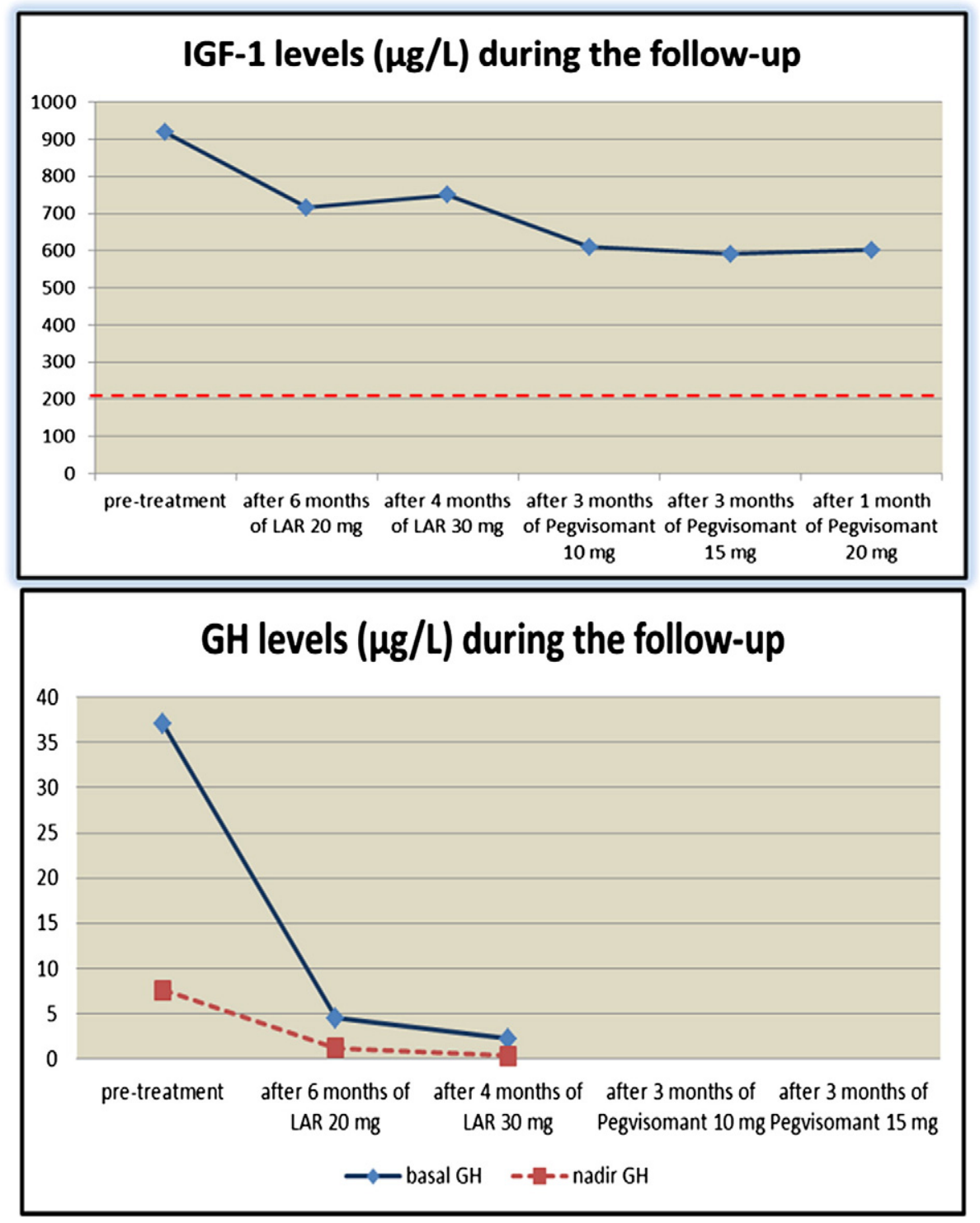

Fig. 3. Graphic representation of divergence between GH and IGF-1 levels during the treatment with different doses of octreotide LAR and Pegvisomant. 
morphologically normal blood cells, an often indolent course and usually a normal lifespan [20]. In about $30 \%$ of cases the mutation is accompanied by thromboembolic events [21], but in JAK2 negative cases thrombotic events could also be detected and the incidence of thrombosis ensuing in JAK2 negative cases does not differ significantly from JAK2 positive patients. The clinical features of these patients are not specific, and could include an increased prevalence in marrow fibrosis and splenomegaly [20], while platelet count and platelet function tests seem not to be influenced by JAK2 V617F positivity [22]. Indeed, no difference in platelet count seems to exist between patients affected by essential thrombocythemia with and without JAK2V617F mutation. In the present case, thrombocythemia represents a primary disease in an acromegalic patient due to the mutation in the JAK2 gene, does not differ from essential thrombocythemia and does not return to normal during acromegaly treatment. In our patient, whether the JAK2 V617F is to be considered as a primary mutation or one secondary to the smoking history is not known. Indeed, accelerated erythropoiesis does seem to render the cells more susceptible to JAK2 mutation among smokers than nonsmokers [23]. Whether the main clinical features of the patient, represented by the severe visceromegaly and difficulty in controlling the disease, are affected by the presence of JAK2 V617F is unclear. In the literature, divergence between GH and IGF-I values are often reported in acromegalic patients, both at diagnosis and during treatment, but the mechanisms of this discrepancy have not been completely explored $[24,25]$. When discrepant results are present, the treatment is usually adjusted on the basis of IGF-1 levels [26]. In patients with persistently elevated IGF-1 levels despite high SA doses, GH receptor antagonist can be used. PEG-V exerts its action peripherally by blocking $\mathrm{GH}$ action rather than centrally, as happens with SA, leading to reduced IGF-1 production in acromegalic patients resistant to SA [27-29]. Different factors, such as circulating estrogens, age or prior radiotherapy may be involved in the GH/IGF-I divergence [15-17]. The impact of GHR polymorphism on the prevalence of discordant levels of GH and IGFI has also been proposed [30]. In addition, among the discrepant patients, the high "IGF-1 phenotype" seems to be associated with a worse metabolic profile [31,32] and this could explain the poor control of diabetes, despite the full dose of metformin and the start of PEG-V treatment, in our patient. In this single case, the impact of GHR autocrine activation and its signal transduction on the post-treatment biochemical assessment of acromegaly remains to be proven. JAK2 V617F is a somatic mutation and all reports to date indicate it is confined to myeloid cells. No data about the presence of JAK2 V617F in non-myeloid cells are available in the literature. Therefore, the mutation should have little impact on liver-produced IGF-I. On the other hand, no data about IGF-1 levels in non-acromegalic patients that are carriers of the JAK2 mutation, nor evidence of IGF-1 production from constitutively activated myeloid cells, are available. We are aware that we are reporting just one clinical case of association between the presence of JAK2 V617F mutation and a peculiar clinical course of acromegaly, but we consider it of interest being the first case ever described of two rare and interesting conditions. Whether this association is casual or causal remains to be proven. More data, on a larger cohort of patients, could suggest that genetic analysis may be helpful in understanding more severe cases of acromegaly and could clarify whether JAK2 V617F mutation has a serious impact on the clinical features and course of acromegaly.

\section{Conflict of interest statement}

None of the authors have any conflict of interest to disclose.

\section{Funding}

This research did not receive any specific grant from any funding agency in the public, commercial or not-for-profit sector.

\section{References}

[1] L.S. Argetsinger, G.S. Campbell, X. Yang, et al., Identification of JAK2 as a growth hormone receptor-associated tyrosine kinase, Cell 74 (2) (1993) 237-244.

[2] A.W. Root, M.J. Root, Clinical pharmacology of human growth hormone and its secretagogues, Curr. Drug Targets Immune Endocr. Metabol. Disord. 2 (1) (2002) 27-52.

[3] R. Kralovics, F. Passamonti, A.S. Buser, et al., A gain-of-function mutation of JAK2 in myeloproliferative disorders, N. Engl. J. Med. 352 (17) (2005) 1779-1790.

[4] B. Cheung, D. Radia, P. Pantelidis, G. Yadegrafar, C. Harrison, The presence of the JAK2 V617F mutation is associated with a higher haemoglobin and increased risk of thrombosis in essential thrombocythaemia, Br. J. Haematol. 132 (2006) 244-245.

[5] P. Sidon, H. El Housni, B. Dessars, P. Heimann, The JAK2V617F mutation is detectable at very low level in peripheral blood of healthy donors, Leukemia 20 (9) (2006) 1622.

[6] C. Martinaud, P. Brisou, M.J. Mozziconacci, Is the JAK2(V617F) mutation detectable in healthy volunteers? Am. J. Hematol. 85 (4) (2010) 287-288.

[7] P. Grellier, P. Chanson, N. Casadevall, S. Abboud, G. Schaison, Remission of polycythemia vera after surgical cure of acromegaly, Ann. Intern. Med. 124 (1996) 495-496.

[8] J.D.N. Nabarro, Acromegaly, Clin. Endocrinol. (Oxf) 26 (1987) 481-512.

[9] P. Mustacchi, M.B. Shimkin, Occurrence of cancer in acromegaly and hypopituitarism, Cancer 10 (1956) 100-104.

[10] J. Barzilay, G.J. Heatley, G.W. Cushing, Benign and malignant tumors in patients with acromegaly, Arch. Intern. Med. 151 (1991) 1629-1632.

[11] P.U. Freda, K.D. Post, J.S. Powell, S.L. Wardlaw, Evaluation of disease status with sensitive measures of growth hormone secretion in 60 postoperative patients with acromegaly, J. Clin. Endocrinol. Metab. 83 (1998) 3808-3816.

[12] G.A. Kaltsas, A.M. Isidori, D. Florakis, et al., Predictors of the outcome of surgical treatment in acromegaly and the value of the mean growth hormone day curve in assessing postoperative disease activity, J. Clin. Endocrinol. Metab. 86 (2001) 1645-1652.

[13] S.S. Damjanovic, A.N. Neskovic, M.S. Petakov, et al., Clinical indicators of biochemical remission in acromegaly: does incomplete disease control always mean therapeutic failure? Clin. Endocrinol. (Oxf) 62 (2005) 410-417.

[14] A.L. Espinosa-de-Los-Monteros, E. Sosa, S. Cheng, et al., Biochemical evaluation of disease activity after pituitary surgery in acromegaly: a critical analysis of patients who spontaneously change disease status, Clin. Endocrinol. (Oxf) 64 (2006) 245-249.

[15] C. Parkinson, W.D. Ryder, P.J. Trainer, The relationship between serum GH and serum IGF-I in acromegaly is gender-specific, J. Clin. Endocrinol. Metab. 86 (2001) 5240-5244.

[16] P.U. Freda, Pitfalls in the biochemical assessment of acromegaly, Pituitary 6 (2003) 135-140.

[17] A.L. Barkan, I. Halasz, K.J. Dornfeld, et al., Pituitary irradiation is ineffective in normalizing plasma insulinlike growth factor I in patients with acromegaly, J. Clin. Endocrinol. Metab. 82 (1997) 3187-3191.

[18] A. Bianchi, A. Giustina, V. Cimino, et al., Influence of growth hormone receptor d3 and full-length isoforms on biochemical treatment outcomes in acromegaly, J. Clin. Endocrinol. Metab. 94 (6) (2009) 2015-2022.

[19] G. Zoppoli, F. Bianchi, A. Bruzzone, et al., Polycythemia as rare secondary direct manifestation of acromegaly: management and single-centre epidemiological data, Pituitary (2011) (Apr 19, Electronic publication ahead of print).

[20] J.L. Spivak, Narrative review: Thrombocytosis, polycythemia vera, and JAK2 mutations: the phenotypic mimicry of chronic myeloproliferation, Ann. Intern. Med. 152 (5) (2010) 300-306.

[21] J.L. Iványi, E. Marton, M. Plander, Significance of the JAK2V617F mutation in patients with chronic myeloproliferative neoplasia, Orv. Hetil. 152 (45) (2011) 1795-1803.

[22] A.E. Tsantes, G.K. Nikolopoulos, P. Tsirigotis, et al, Direct evidence for normalization of platelet function resulting from platelet count reduction in essential thrombocythemia, Blood Coagul. Fibrinolysis 22 (6) (2011) 457-462.

[23] I. Weinberg, A. Borochowitz, S. Krichevski, R. Perlman, A. Ben-Yehuda, D. BenYehuda, Janus Kinase V617F mutation in cigarette smokers, Am. J. Hematol. 87 (1) (2012) 5-8.

[24] E.O. Machado, G.F. Taboada, L.V. Neto, et al., Prevalence of discordant GH and IGF-I levels in acromegalics at diagnosis, after surgical treatment and during treatment with octreotide LAR, Growth Horm. IGF Res. 18 (5) (2008) 389-393.

[25] M. Matta, V. Bongard, S. Grunenwald, J.C. Maiza, A. Bennet, P. Caron, Clinical and metabolic characteristics of acromegalic patients with high IGF-I/normal GH levels during somatostatin analog treatment, Eur. J. Endocrinol. 164 (6) (2011) 885-889.

[26] P.U. Freda, Monitoring of acromegaly: what should be performed when GH and IGF-1 levels are discrepant? Clin. Endocrinol. (Oxf) 71 (2) (2009) 166-170.

[27] V.S. Herman-Bonert, K. Zib, J.A. Scarlett, S. Melmed, Growth hormone receptor antagonist therapy in acromegalic patients resistant to somatostatin analogs, J. Clin Endocrinol. Metab. 85 (8) (2000) 2958-2961.

[28] A.J. van der Lely, W.W. de Herder, S.W. Lamberts, New medical treatment for acromegaly, Pituitary 2 (1) (1999) 89-92.

[29] P.J. Trainer, W.M. Drake, L. Katznelson, et al., Treatment of acromegaly with the growth hormone-receptor antagonist pegvisomant, N. Engl. J. Med. 342 (16) (2000) 1171-1177

[30] A. Bianchi, A. Giustina, V. Cimino, et al., Influence of growth hormone receptor d3 and full-length isoforms on biochemical treatment outcomes in acromegaly, J. Clin. Endocrinol. Metab. 94 (6) (2009) 2015-2022.

[31] O. Alexopoulou, M. Bex, R. Abs, G. T'Sjoen, B. Velkeniers, D. Maiter, Divergence between growth hormone and insulin-like growth factor-i concentrations in the follow-up of acromegaly, J. Clin. Endocrinol. Metab. 93 (4) (2008) 1324-1330.

[32] O. Serri, C. Beauregard, J. Hardy, Long-term biochemical status and diseaserelated morbidity in 53 postoperative patients with acromegaly, J. Clin. Endocrinol. Metab. 89 (2004) 658-661. 